\title{
Proteasome modulator 9 (PSMD9) gene rs14259 polymorphism in Alzheimer's disease
}

\author{
Ozer $\mathrm{Y}^{1}$, Ozen $\mathrm{F}^{2}$, Diler $\mathrm{Y}^{3}$, Yalcin $\mathrm{AD}^{3}$, Atasever-Arslan $\mathrm{B}^{4,5}$ \\ Department of Molecular Biology and Genetics, Faculty of Engineering and Natural Sciences, \\ Uskudar University, Istanbul, Turkey. belkisatasever.arslan@uskudar.edu.tr
}

\begin{abstract}
AIM: Alzheimer's disease $(A D)$ is a progressive and fatal neurodegenerative disorder resulting in degeneration of certain neuronal structures in certain brain regions and severe neuronal loss, characterized by a pathological accumulation of senile amyloid plaques (SP) and neurofibrillary tangles (NFT) within the brain . Alzheimer's disease has been associated with Type 2 diabetes mellitus (T2DM) in recent years. We designed our study on the relationship between AD and T2DM. Genome screening studies in different populations had linked the chromosome 12q24 region to type 2 diabetes. Within this region, there is the PSMD9 gene encoding a transcriptional coactivator of insulin production.

METHOD: The effect of PSMD9 gene E197G (rs14259) polymorphism on AD was investigated in29

Alzheimer's patients and 25 healthy controls, who were included in the study.

RESULTS: In our study, it was determined that the variant of PSMD9 gene E197G (rs14259) did not cause genetic risk factor for Alzheimer's disease in Turkish population.

CONCLUSIONS: Our study was the first to investigate the relationship between PSMD9 gene and Alzheimer's disease. A larger sample group is needed to investigate the contribution of the PSMD9 gene to Alzheimer's disease in further studies (Tab. 5, Ref. 8). Text in PDF www.elis.sk.
\end{abstract}

KEY WORDS: PSMD9, Alzheimer's disease, rs14259.

\section{Introduction}

Alzheimer's disease (AD) is a multifactorial neurodegenerative disease including many genetic and environmental factors (Chang et al, 2016, Li et al, 2008). The brain of the patients with $\mathrm{AD}$ is essentially characterized by neuronal and synaptic loss, extracellular plaques composed of amyloid- $\beta$ peptides, and intraneuronal neurofibrillary tangles consisting of hyperphosphorylated tau proteins (Saraswati et al, 2018,

Yang et al, 2015). However, damaged and toxic misfolded proteins are associated with many neurodegenerative diseases (de Nazareth, 2017).

Proteasome modulator 9 (PSMD9) is a part of the 26S proteasome complex degrading intracellular proteins in the immune response and antigen presentation by MHC class I cells. It was demonstrated that PSMD9 inhibited tumor necrosis factor $\alpha$ (TNF-

\footnotetext{
'Neuroscience Program, Health Sciences Institute, Uskudar University, Istanbul, Turkey, ${ }^{2}$ Department of Bioengineering, Faculty of Engineering and Natural Sciences, Uskudar University, Istanbul, Turkey, ${ }^{3}$ Neurology Clinic, Ümraniye Research and Training Hospital, Istanbul, Turkey, ${ }^{4}$ Department of Molecular Biology and Genetics, Faculty of Engineering and Natural Sciences, Üsküdar University, Istanbul, Turkey, and ${ }^{5}$ Department of Anatomy and Cell Biology, University of Illinois at Chicago, Chicago Illinois, United States of America
}

Address for correspondence: $\mathrm{B}$. Atasever-Arslan, $\mathrm{PhD}$, Department of Molecular Biology and Genetics, Faculty of Engineering and Natural Sciences, Uskudar University, Istanbul, Turkey. $\alpha)$-mediated NF-kB activation via inhibition of nuclear factor $\mathrm{kB} \alpha$ $(\mathrm{IkB} \alpha)$ proteasome degradation (Hao et al, 2015). TNF- $\alpha$ is one determinant of $\mathrm{AD}$ and T2DM onset and progression (Tsutsui and Hays, 2018). In addition, the proteasome-mediated proteolysis plays a recognized role in neuronal development, synaptic plasticity, and protein quality control (Hao et al, 2015). Thus, PSMD9 variants might play a role in neuroinflammation and many neurodegenerative diseases. Recent studies imply that PSMD9 variants may attend pathogenesis of neuro-psychiatric disorders. However, effects of PSMD9 variants on neurotoxic aggregated protein forms in neurodegenerative diseases are unknown.

In order to assess the involvement of PSMD9 gene rs14259 polymorphism in the risk of AD in Turkey, we evaluated the genotype and allele distributions of PSMD9 rs14259 polymorphism in $\mathrm{AD}$ patients and the controls.

\section{Methods}

\section{Participants}

Twenty-nine patients with Alzheimer's disease, who were diagnosed as Alzheimer's disease according to NINCDS-ADRDA criteria applied to the Umraniye Education and Research Hospital, Department of Neurology, Istanbul. Twenty-five control participants, who were admitted to the same hospital without any neurological, oncological and rheumatologic diseases were included in this study. The study methods conformed to the ethical guidelines of the Declaration of Helsinki and were approved by the Umra- 
niye Education and Research Hospital Ethics Committee and all the patients and the controls gave a written informed consent to participate in the study.

\section{Genotyping}

Blood samples from 58 participants ( 29 patients, 25 controls) were collected in tubes with EDTA. DNA was isolated from peripheral blood samples by using UltraClean BloodSpin DNA Isolation Kit. The genotyping of PSMD9 gene rs14259 polymorphism were performed by using TIB MolBiol LightCycler ${ }^{\circledR}$ FastStart DNA Master HybProbe PCR kit, according to the manufacturer's instructions.

\section{Statistical evaluation}

IBM Statistical Product and Service Solutions (SPSS) Statistic 23 program was used for a statistical analysis of the results. The relationship between genotype and allele distribution of PSMD9 rs14259 polymorphism was obtained using a chi-square (X2) analysis. Compliance of patient and the control groups to the HardyWeinberg Balance (HWE) test Michael H. Court's (2005-2008) Excel-based HWE online calculator was used. Mann-Whitney test was used to compare the ages of the patients and the controls because it did not show normal distribution. In $\mathrm{AD}$ patients and the controls, the dominant model was formed by logistic regression analysis. Homozygous wild genotype and heterozygous and homozygous variant individuals were included in the same group and the effect of rs14259 polymorphism according to the dominant model in AD susceptibility was evaluated. All $p$ values $<0.05$ were considered significant.

\section{Results}

29 Alzheimer patients (75.28) and 25 controls (69.76) were included in our study. The normality of the age distributions was

Tab. 1. The Mean age of AD patients and controls group.

\begin{tabular}{|c|c|c|c|c|c|}
\hline & \multicolumn{2}{|c|}{$\begin{array}{c}\text { AD patients } \\
\mathrm{n}=29\end{array}$} & \multicolumn{2}{|c|}{$\begin{array}{c}\text { Controls } \\
n=25\end{array}$} & \multirow[t]{2}{*}{$\mathrm{p}^{*}$} \\
\hline & Rank average & SD & Rank average & SD & \\
\hline Age & 31.21 & 90.00 & 23.20 & 580.00 & 0.063 \\
\hline
\end{tabular}

*Mann-Whitney test

Tab. 2 Distribution of AD patients and controls group by sex.

\begin{tabular}{lcccccc}
\hline & \multicolumn{2}{c}{ AD patients } & & \multicolumn{2}{c}{ Controls } & \multirow{2}{*}{$\mathrm{p}$} \\
\cline { 2 - 3 } & Count & $\%$ & & Count & $\%$ & \\
\hline Age Female & 13 & 44.8 & & 13 & 52 & \multirow{2}{*}{0.800} \\
Age Male & 16 & 55.2 & & 12 & 48 & \\
\hline Total & 29 & 100.0 & & 25 & 100.0 & \\
\hline
\end{tabular}

* chi-square $\left(\mathrm{X}^{2}\right)$ test

Tab. 3. The Hardy-Weinberg Equilibrium Test (HWE) value of the controls and $\mathrm{AD}$ patients group.

\begin{tabular}{lcc}
\hline & Hardy-Weinberg $\mathrm{X}^{2}$ & $\mathrm{p}$ \\
\hline AD patientrs & 2.935 & 0.086 \\
Controls & 0.056 & 0.811 \\
\hline
\end{tabular}

Tab. 4. Distribution of the PSMD9 genotypes and alleles in AD patients and controls group.

\begin{tabular}{|c|c|c|c|c|c|c|c|}
\hline & & \multicolumn{2}{|c|}{$\begin{array}{c}\text { AD patients } \\
n=29\end{array}$} & \multicolumn{2}{|c|}{$\begin{array}{c}\text { Controls } \\
n=25\end{array}$} & \multirow[t]{2}{*}{$X^{2}$} & \multirow{2}{*}{$\mathrm{p}^{*}$} \\
\hline & & Count & $\%$ & Count & $\%$ & & \\
\hline \multirow{3}{*}{ Genotypes } & $\mathrm{AA}$ & 15 & 51.7 & 12 & 48 & \multirow{3}{*}{2.046} & \multirow{3}{*}{0.459} \\
\hline & $\mathrm{AG}$ & 14 & 48.3 & 11 & 44 & & \\
\hline & GG & 0 & 0.0 & 2 & 8 & & \\
\hline Alleles & $\begin{array}{l}\text { A } \\
\text { G }\end{array}$ & & & & & & \\
\hline
\end{tabular}

*p value was obtained as a result of chi-square $\left(\mathrm{X}^{2}\right)$ test.

Tab. 5. Logistic regression analysis of PSMD 9 polymorphism in AD patients and controls.

\begin{tabular}{lccc}
\hline Models & $\mathrm{p}^{*}$ & OR** & $\% 95 \mathrm{CI}$ \\
\hline Dominant & 0.785 & 0.862 & $0.295-2.513$ \\
Additive & 0.451 & 0.694 & $0.269-1.794$ \\
\hline
\end{tabular}

*Logistic regression **Odds Ratio

examined in the patient and the control groups and non-parametric Mann-Whitney test was used, since it did not show normal distribution. According to the test results, $\mathrm{p}$ value was calculated as 0.063 and there was no statistically significant difference between the patient and the control groups regarding the age. The mean values and standard deviations of patients and the controls are given in Table 1 .

In the patient group, there were 13 women and 16 men; the control group consisted of 13 female and 12 male individuals. Chi-square (X2) test was used to assess whether there was a statistical difference between the patient and the control groups. The $p$ value was found to be 0.800 for gender distribution between the two groups. The results were shown in Table 2.

The suitability and adequacy of controls and $\mathrm{AD}$ patients were tested by the Hardy-Weinberg Balance Test (HWE) after determining the genotype and allele distribution of the patients and controls. Compliance of patient and the control groups to Hardy-Weinberg Balance (HWE) test was obtained by using Michael H. Court's (2005-2008) Excel-based HWE online calculator. According to the calculated results, it is in accordance with Hardy-Weinberg equation in both groups. The $\mathrm{p}$ values of the patient and control groups are shown in Table 3.

Genotype distributions of rs14259 A / G polymorphism of PSMD9 gene for AD patients and controls were compared using chi-square (X2) test. When the genotype frequencies were compared statistically using AA, AG, GG chi-square test, there was not any statistically significant difference between the patient and the control groups. In AD patients, 15 individuals had AA and 14 individuals had AG genotype, whereas there was no GG genotype. In the control group, 12 individuals had AA genotype, 11 individuals had AG genotype and 2 individuals had GG genotype. Genotype frequency distributions of the groups were shown in Table 4.

Allele distribution between $\mathrm{AD}$ patients and the controls was examined by chi-square (X2) test. While A is the major allele, $\mathrm{G}$ is the minor allele thought to have an effect on the allele. However, there was no significant difference in $\mathrm{A}$ and $\mathrm{G}$ allele frequencies for two groups (Tab. 4). 
Risk assessment of rs14259 polymorphism in Alzheimer's disease susceptibility was examined by logistic regression analysis according to dominant model and additive model. In AD patients, since there was no variant homozygous GG genotype, a recessive genetic model analysis could not be performed. According to the dominant model; individuals with variant homozygous genotype and individuals with heterozygous genotype were included in the same group and compared with individuals having homozygous wild genotype. ( $\mathrm{GG}+\mathrm{AG} / \mathrm{AA}) \mathrm{We}$ aimed to investigate whether AA genotype is a protective factor in Alzheimer's disease with the dominant model. However, a statistical significance was not achieved (Tab. 5). In addition, the allele distribution of two groups was examined according to the additive model. In this model, the effect of G, which is thought to affect the disease, was investigated. There was no statistically significant effect on the test result. The $p$ value, odds ratio values and confidence interval values of the evaluation are given in Table 5.

\section{Discussion}

Hereditary factors can affect both familial and sporadic forms of Alzheimer's disease. The mechanisms of sporadic Alzheimer's disease is still not fully understood. Although the Apo E gene was known to be major genetic risk factor increasing the likelihood of Alzheimer's disease, the association is seen in $40 \%$ of patients with a late onset AD (Ghosh T et al, 2012).

Given the studies supporting the association of Alzheimer's disease with T2DM, understanding the role of common signal pathways in the pathogenesis of these diseases is important for both resolving the mechanistic bases of the relationship between the two diseases and developing new diagnostic and therapeutic methods. These data suggest that any association identifiable with PSMD9 rs14259 polymorphism with AD according to gender, CDR and MMSE results. This is the first study conducted in Turkey on the relationship between the frequency of PSMD9 gene rs14259 polymorphism and AD.

There were some limitations in the study. We evaluated the association between PSMD9 gene rs14259 polymorphism and Alzheimer disease, but we could not examine the PSMD9 gene expression and protein levels in our study group. Although there were no significant results associated with PSMD9 gene rs14259 polymorphism, investigation of the association between genetic variants of 26s subunits and Alzheimer's disease can contribute to understand the underlying mechanism of neurotoxic aggregate formation.

\section{References}

1. Chang XL, Tan L, Tan MS, Wang HF, Tan CC, Zhang W, Zheng ZJ, Kong LL, Wang ZX, Jiang T, Yu JT, Tan L. Association of HMGCR polymorphism with late-onset Alzheimer's disease in Han Chinese. Oncotarget 2016; 7 (16): 22746-22751.

2. de Nazareth AM. Type 2 diabetes mellitus in the pathophysiology of Alzheimer's disease. Dement Neuropsychol 2017; 11 (2): 105-113.

3. Ghosh T, Mustafa M, Kumar V, Datta SK, Bhatia MS, Sircar S, Banerjee BD. A preliminary study on the influence of glutathione $S$ transferase T1 (GSTT1) as a risk factor for late onset Alzheimer's disease in North Indian population. Asian J Psychiatr 2012; 5 (2): 160-163.

4. Hao H, Haas MJ, Wu R, Gragnoli C. T2D and Depression Risk Gene Proteasome Modulator 9 is Linked to Insomnia. Sci Rep 2015; 5: 12032.

5. Li H, Wetten S, Li L, St Jean PL, Upmanyu R, Surh L, Hosford D, Barnes MR, Briley JD, Borrie M, Coletta N, Delisle R, Dhalla D, Ehm MG, Feldman HH, Fornazzari L, Gauthier S, Goodgame N, Guzman D, Hammond S, Hollingworth P, Hsiung GY, Johnson J, Kelly DD, Keren R, Kertesz A, King KS, Lovestone S, Loy-English I, Matthews PM, Owen MJ, Plumpton M, Pryse-Phillips W, Prinjha RK, Richardson JC, Saunders A, Slater AJ, St George-Hyslop PH, Stinnett SW, Swartz JE, Taylor RL, Wherrett J, Williams J, Yarnall DP, Gibson RA, Irizarry MC, Middleton LT, Roses AD. Candidate single-nucleotide polymorphisms from a genomewide association study of Alzheimer disease. Arch Neurol 2008; 65 (1): 45-53.

6. Saraswati AP, Ali Hussaini SM, Krishna NH, Babu BN, Kamal A. Glycogen synthase kinase-3 and its inhibitors: Potential target for various therapeutic conditions. Eur J Med Chem 2018; 144: 843-858.

7. Tsutsui Y, Hays FA. A Link between Alzheimer's and Type II Diabetes Mellitus? Ca+2 -Mediated Signal Control and Protein Localization. Bioessays 2018; 40 (6): e1700219.

8. Yang L, Zhou HH, Ye YF, Fan XW, Wang YJ, Meng Y. Association of PS1 1/2, ACE I/D, and LRP C/T polymorphisms with Alzheimer's disease in the Chinese population: a meta-analysis of case-control studies. Genet Mol Res 2015; 14 (1): 1017-1024. 